\title{
Treatment of patients with COPD and recurrent exacerbations: the role of infection and inflammation
}

This article was published in the following Dove Press journal:

International Journal of COPD

II March 2016

Number of times this article has been viewed

\author{
Salud Santos ${ }^{1,2}$ \\ Alicia Marin ${ }^{2,3}$ \\ Joan Serra-Batlles ${ }^{4}$ \\ David de la Rosa ${ }^{5}$ \\ Ingrid Solanes 6 \\ Xavier Pomares ${ }^{7}$ \\ Marta López-Sánchez' \\ Mariana Muñoz-Esquerre' \\ Marc Miravitlles 2,8 \\ 'Pneumology Department, \\ Hospital Universitari de Bellvitge, \\ Universidad de Barcelona, Bellvitge \\ Biomedical Research Institute \\ (IDIBELL), Hospitalet de Llobregat, \\ Barcelona, ${ }^{2}$ Centro de Investigación \\ Biomédica en Red de Enfermedades \\ Respiratorias (CIBERES), Madrid, \\ ${ }^{3}$ Pneumology Department, Hospital \\ Universitari Germans Trias i Pujol, \\ Badalona, ${ }^{4}$ Pneumology Department, \\ Hospital Universitari de Vic, \\ ${ }^{5}$ Pneumology Unit, Hospital Plató, \\ ${ }^{6}$ Pneumology Department, Biomedical \\ Research Institute Sant Pau, \\ Hospital de la Santa Creu i Sant Pau, \\ Universidad Autónoma, Barcelona, \\ ${ }^{7}$ Pneumology Department, Hospital \\ Universitari Parc Taulí, Sabadell, \\ ${ }^{8}$ Pneumology Department, Hospital \\ Universitari Vall d'Hebron, Barcelona, \\ Spain
}

Correspondence: Marc Miravitlles Pneumology Department, Hospital Universitari Vall d'Hebron,

Passeig de la Vall d'Hebron II9-129, 08035 Barcelona, Spain

Tel/fax +34932746083

Email mmiravitlles@vhebron.net

\begin{abstract}
Exacerbations of COPD represent an important medical and health care problem. Certain susceptible patients suffer recurrent exacerbations and as a consequence have a poorer prognosis. The effects of bronchial infection, either acute or chronic, and of the inflammation characteristic of the disease itself raise the question of the possible role of antibiotics and antiinflammatory agents in modulating the course of the disease. However, clinical guidelines base their recommendations on clinical trials that usually exclude more severe patients and patients with more comorbidities, and thus often fail to reflect the reality of clinicians attending more severe patients. In order to discuss aspects of clinical practice of relevance to pulmonologists in the treatment and prevention of recurrent exacerbations in patients with severe COPD, a panel discussion was organized involving expert pulmonologists who devote most of their professional activity to day hospital care. This article summarizes the scientific evidence currently available and the debate generated in relation to the following aspects: bacterial and viral infections, chronic bronchial infection and its treatment with cyclic oral or inhaled antibiotics, inflammatory mechanisms and their treatment, and the role of computerized tomography as a diagnostic tool in patients with severe COPD and frequent exacerbations.
\end{abstract}

Keywords: COPD exacerbation, treatment, bronchial infection, anti-inflammatory treatment, antibiotics

\section{Introduction}

COPD is a progressive and heterogeneous chronic entity. One particular group of patients with COPD is highly susceptible to recurrent exacerbations that in turn increase the severity of the condition. At the same time, patients with greater functional severity are more likely to experience exacerbations. ${ }^{1}$ In most instances, the high frequency of exacerbations remains quite stable over time, and so this subset of patients is assigned a specific phenotype, "the frequent exacerbator phenotype". 1,2 Few studies have focused specifically on the treatment of patients with frequent exacerbations, and the standard recommendations for COPD in clinical practice guidelines - conventional treatment with bronchodilators (BDs) and inhaled corticosteroids (ICSs), and preventive measures such as influenza and pneumococcal vaccinations - may not be sufficient to completely prevent exacerbations in these challenging patients. It is not known why certain patients exhibit the frequent exacerbator phenotype, nor has it been established how far recurrent infections, defects in the individual's own immune system, or the inflammatory nature of COPD may cause the presence of repeated exacerbations. ${ }^{3}$

The involvement of viruses and bacteria in exacerbations of COPD, and the possible roles of systemic and bronchial inflammation, and of the individual's 
defense mechanisms are receiving increasing attention. Anti-inflammatory therapy (mainly ICSs) may be beneficial in exacerbators, but it may also produce a degree of immunosuppression and favor bacterial growth. ${ }^{4}$

Clinical trials provide scientific evidence of the efficacy of drugs and can help to guide the decision-making process, though in itself, the information they yield may not be sufficient. Not all aspects of clinical practice with real-life patients are covered in the medical literature, and therefore, expert discussions regarding disease management in less frequent and more complex situations are relevant. In order to discuss aspects of clinical practice of importance to specialists in the treatment and prevention of recurrent exacerbations in patients with more severe COPD, a debate was organized involving expert pulmonologists who have devoted many years to patient care in the day hospital setting. This article summarizes the scientific evidence currently available, the points discussed, and the recommendations reached after the debate.

\section{The role of infection in recurrent exacerbations of COPD and prevention strategies}

The pathophysiology of COPD exacerbations is complex. From a clinical standpoint, not all exacerbations are similar, and they do not all respond to the same treatments. Cluster analyses of biomarkers capable of distinguishing between various etiologies of exacerbations have identified four main groups or phenotypes: 1) bacterial, 2) viral, 3) eosinophilic, and 4) pauci-inflammatory. The most common is the infectious phenotype, which occurs in $85 \%$ of cases $(55 \%$ bacterial and $30 \%$ viral), followed by the eosinophilic phenotype (30\%). ${ }^{5}$ Among the microorganisms involved in infectious exacerbations, the most common bacteria are Haemophilus influenzae, followed by Streptococcus pneumoniae and Moraxella catarrhalis. However, in patients with severe COPD who receive more antibiotic treatments or experience more severe exacerbations, Pseudomonas aeruginosa (PA) and Enterobacteriaceae are more frequently observed. ${ }^{6}$ Regarding viral etiology, the most common is the rhinovirus, followed by the parainfluenza virus, influenza, and the respiratory syncytial virus. Up to $25 \%$ of patients may have viral and bacterial coinfection. ${ }^{7}$

The evidence about the involvement of viruses in exacerbations of COPD is growing. In a human experimental model in which rhinovirus was inoculated in patients with COPD and healthy subjects, it was observed that patients with COPD had more severe respiratory symptoms, with a more pronounced deterioration in lung function and increased local inflammatory response. ${ }^{8}$ It has also been reported that patients with COPD inoculated with rhinovirus showed an exponential growth in bacterial load over the following days, especially $H$. influenzae, compared with smokers without COPD and nonsmokers. This suggests that rhinovirus infection may cause a change in the microbiome of patients with COPD or in their defense mechanisms, which facilitates subsequent bacterial infection. ${ }^{9}$ It has also been shown that patients with rhinovirus in their airways were more likely to suffer from exacerbations, a finding that underlines the impact of viral infection on the development of exacerbations of COPD. ${ }^{7}$

An important factor in the recurrent bacterial exacerbations is chronic bronchial infection (CBI). CBI is defined as the presence of potentially pathogenic microorganisms (PPMs) in the lower airways of patients with stable COPD and has been associated with both local and systemic inflammatory reactions. ${ }^{10} \mathrm{CBI}$ can be identified by chronic production of sputum, sometimes purulent, often associated with the presence of bronchiectasis and PPMs such as $H$. influenzae and PA in serial sputum cultures ${ }^{10,11}$ and has been related to loss of pulmonary function, worsening of health status, and increased frequency of exacerbations. ${ }^{10}$

In this group of patients, several prophylactic antibiotic regimens have been tested to assess their ability to prevent exacerbations by reducing the bacterial load and/or by preventing the acquisition of new strains, as well as other inflammatory and immunomodulatory mechanisms (Table 1). These regimens are used in patients who present a frequent exacerbator phenotype of infectious origin, despite appropriate pharmacological and nonpharmacological treatment. The most common regimens are 1) continuous administration of macrolides, 2) intermittent quinolones, and 3) long-term use of inhaled antibiotics. ${ }^{12}$

Since the demonstration of the efficacy of macrolides in the treatment of diffuse panbronchiolitis, their use has been evaluated in many chronic respiratory diseases, and particularly in cystic fibrosis. In addition to their antimicrobial action, macrolides have a notable anti-inflammatory effect that decreases the bacterial load and virulence. They also reduce airway secretions and thus promote mucociliary clearance. ${ }^{13}$ Among the most important clinical trials of the efficacy of prolonged use of macrolides for the prevention of COPD exacerbations, the study by Albert et al compared the daily administration of $250 \mathrm{mg}$ azithromycin versus placebo over a year in critically ill patients (but who were not necessarily selected for frequent exacerbations). ${ }^{14}$ 
Table I Clinical studies of antibiotic treatment for COPD in the stable phase

\begin{tabular}{|c|c|c|c|}
\hline Study & $\begin{array}{l}\text { Design and treatment } \\
\text { groups }\end{array}$ & Patient population & Results \\
\hline Gómez et al ${ }^{56}$ & $\begin{array}{l}\text { Nonrandomized, open, } \\
\text { comparative study of } \\
94 \text { patients: } 54 \text { treated with } \\
\text { azithromycin } 500 \mathrm{mg} / \text { day } \\
\text { for } 3 \text { days every } 3 \text { weeks } \\
\text { from September to May, and } \\
40 \text { receiving standard care }\end{array}$ & $\begin{array}{l}\text { Mean age } 67.6 \text { years, recruited after } \\
\text { admission due to exacerbation and } \\
\text { a mean of six exacerbations in the } \\
\text { previous year }\end{array}$ & $\begin{array}{l}\text { Significant reduction in exacerbations and } \\
\text { hospital admissions in the azithromycin group }\end{array}$ \\
\hline Suzuki et al ${ }^{57}$ & $\begin{array}{l}\text { Randomized, nonblind study in } \\
109 \text { patients: } 55 \text { treated with } \\
\text { erythromycin } 200-400 \mathrm{mg} / \mathrm{day} \\
\text { and } 54 \text { in the control group, } \\
\text { for I year }\end{array}$ & $\begin{array}{l}\text { Mean age } 70 \text { years, mean FEV, between } \\
\text { I.3 and I. } 47 \mathrm{~L}\end{array}$ & $\begin{array}{l}\text { Significant reduction in common infections } \\
\text { and exacerbations in the antibiotic-treated } \\
\text { group }\end{array}$ \\
\hline Seemungal et a ${ }^{58}$ & $\begin{array}{l}\text { Randomized, double-blind, } \\
\text { placebo-controlled study. } \\
\text { 109 patients: } 53 \text { treated with } \\
\text { erythromycin } 250 \text { mg twice } \\
\text { daily, and } 56 \text { with placebo for } \\
\text { I year }\end{array}$ & Mean age 67.2 years, mean FEV, 50\% & $\begin{array}{l}\text { Significant reduction in the frequency of } \\
\text { exacerbations with antibiotics }(35 \%, P=0.006) \text {. } \\
\text { The mean time to first exacerbation was } 27 \text { I } \\
\text { versus } 89 \text { days in the placebo arm }(P=0.02) \text {. } \\
\text { Significant reduction in the duration of the } \\
\text { exacerbation with macrolide }\end{array}$ \\
\hline Pomares et al ${ }^{59}$ & $\begin{array}{l}\text { Retrospective study of } \\
24 \text { patients with COPD } \\
\text { treated with azithromycin } \\
500 \mathrm{mg} \text { three times per week } \\
\text { for I year }\end{array}$ & $\begin{array}{l}\text { Mean age } 70.9 \text { years, mean FEV, } 32.2 \% \text {, } \\
\text { mean of } 3.3 \text { hospitalizations and seven } \\
\text { exacerbations in the previous year }\end{array}$ & $\begin{array}{l}58.9 \% \text { reduction in exacerbations and } 61.2 \% \\
\text { reduction in hospitalizations compared to the } \\
\text { previous year without macrolides }\end{array}$ \\
\hline He et al ${ }^{60}$ & $\begin{array}{l}\text { Randomized, double-blind, } \\
\text { placebo-controlled study of } \\
36 \text { patients: } 18 \text { treated with } \\
\text { erythromycin } 125 \mathrm{mg} \text { three } \\
\text { times daily, and } 18 \text { with } \\
\text { placebo }\end{array}$ & Mean age 69 years, mean FEV, $43 \%$ & $\begin{array}{l}\text { Significant reduction in the total number } \\
\text { of cells in sputum and neutrophil elastase. } \\
\text { Significant reduction ( } 44 \%) \text { in the relative risk } \\
\text { of exacerbation with antibiotics. Significant } \\
\text { delay in time to first exacerbation with } \\
\text { macrolide }\end{array}$ \\
\hline Blasi et $\mathrm{al}^{61}$ & $\begin{array}{l}\text { Open, randomized, } \\
\text { noncontrolled study of } \\
22 \text { patients with COPD and } \\
\text { tracheostomy: II receiving } \\
\text { azithromycin } 500 \mathrm{mg} 3 \text { days } \\
\text { per week for } 6 \text { months, and II } \\
\text { in the usual care group }\end{array}$ & $\begin{array}{l}\text { Mean age } 72 \text { and } 73 \text { years. No } \\
\text { information on lung function. } 91 \% \text { and } \\
73 \% \text { were colonized }\end{array}$ & $\begin{array}{l}\text { Time to first exacerbation was significantly } \\
\text { longer with the macrolide. Hazard ratio for } \\
\text { the first exacerbation associated with usual } \\
\text { care was } 5.4 \text { I ( } 95 \% \text { Cl: I.67-17.5). Significant } \\
\text { reduction in hospitalizations with azithromycin }\end{array}$ \\
\hline Albert et al ${ }^{14}$ & $\begin{array}{l}\text { Randomized, double-blind, } \\
\text { placebo-controlled clinical trial } \\
\text { in I, } 142 \text { patients: } 570 \text { received } \\
\text { azithromycin } 250 \mathrm{mg} \text { daily, and } \\
572 \text { received placebo }\end{array}$ & $\begin{array}{l}\text { Mean age } 66 \text { years. Mean } \mathrm{FEV}, 39 \%-40 \% \text {; } \\
>50 \% \text { had required hospital visits for } \\
\text { exacerbation in the previous year }\end{array}$ & $\begin{array}{l}\text { Significantly reduced risk of exacerbations } \\
\text { with azithromycin }(P<0.00 \mathrm{I}) \text {. Median } \\
\text { time to first exacerbation was significantly } \\
\text { prolonged: I } 74 \text { days with placebo and } 266 \\
\text { with macrolide. Hazard ratio for time to first } \\
\text { exacerbation was } 0.7 \text { I }(95 \% \mathrm{Cl}: 0.6 \mathrm{I}-0.83 \text {; } \\
P<0.00 \text { I) }\end{array}$ \\
\hline Uzun et al ${ }^{16}$ & $\begin{array}{l}\text { Randomized, double-blind, } \\
\text { placebo-controlled clinical study } \\
\text { in } 92 \text { patients with COPD: } \\
47 \text { treated with azithromycin } \\
500 \mathrm{mg} 3 \text { days a week for } \\
\text { I year, and } 45 \text { with placebo }\end{array}$ & $\begin{array}{l}\text { COPD with at least three exacerbations } \\
\text { in the previous year. No significant } \\
\text { bronchiectasis }\end{array}$ & $\begin{array}{l}\text { Significant reduction }(42 \%) \text { in the rate of } \\
\text { exacerbations in the azithromycin group } \\
\text { compared to placebo }\end{array}$ \\
\hline Sethi et al ${ }^{17}$ & $\begin{array}{l}\text { Randomized, double-blind, } \\
\text { placebo-controlled study of } \\
\text { I,I57 patients: } 573 \text { received } \\
\text { moxifloxacin } 400 \mathrm{mg} \text { once a } \\
\text { day for } 5 \text { days, repeated cycles } \\
\text { every } 8 \text { weeks for a total of six } \\
\text { cycles, compared to placebo }\end{array}$ & $\begin{array}{l}\text { Mean age } 66 \text { years, mean } \mathrm{FEV}, 40 \% \text {, } \\
\text { with at least two exacerbations in the } \\
\text { previous year }\end{array}$ & $\begin{array}{l}\text { Significant reduction }(25 \%) \text { of exacerbations } \\
\text { with moxifloxacin }(P=0.046) .45 \% \text { reduction } \\
\text { in exacerbations in patients with purulent/ } \\
\text { mucopurulent sputum at the time of inclusion } \\
(\mathrm{OR}=0.55,95 \% \mathrm{Cl}: 0.36-0.84 ; P=0.006)\end{array}$ \\
\hline
\end{tabular}

Abbreviations: $\mathrm{FEV}_{1}$, forced expiratory volume in I second; $\mathrm{Cl}$, confidence interval; OR, odds ratio. 
Compared to placebo, treatment with azithromycin resulted in a significant decrease $(27 \%)$ in exacerbation frequency and significantly prolonged the time to first exacerbation. Interestingly, in a responder analysis, azithromycin had less effect on patients who were active smokers. ${ }^{15}$ Adverse events with azithromycin have also been reported, such as an increase in the proportion of nasopharyngeal colonization by macrolide-resistant pathogens and a higher frequency of hearing disturbances, among others. ${ }^{14}$ In the study by Albert et al, because the presence of microorganisms in sputum at the end of treatment was significantly lower in the macrolide group (despite the higher proportion of resistant pathogens in these patients), their absolute numbers were lower than in the placebo group, and so it is unclear whether long-term use of macrolides does indeed lead to a global increase in resistance. Another important study compared treatment with $500 \mathrm{mg}$ of azithromycin 3 days per week for 1 year versus placebo, and included patients with COPD who had at least three exacerbations in the previous year and did not present significant bronchiectasis. The results were also positive and showed a significant reduction (42\%) in the rate of exacerbations with azithromycin compared with placebo. ${ }^{16}$

The PULSE study compared the administration of six 5-day cycles of moxifloxacin (400 mg) every 2 months for 1 year compared to placebo. ${ }^{17}$ This study included patients with the frequent exacerbator phenotype and chronic bronchitis who had had at least two exacerbations in the previous year and were not colonized by PPMs resistant to moxifloxacin (specifically, resistant PA or Stenotrophomonas). Treatment with moxifloxacin reduced the risk of exacerbations by $25 \%$ overall and by $45 \%$ in patients who had purulent sputum at baseline (ie, those with probable CBI). No increase was observed in bacterial resistances to antibiotics, and no serious adverse events due to the treatment were recorded. ${ }^{17}$

In summary, the choice of long-term antibiotic therapy should carefully evaluate the advantages and disadvantages. Long-term antibiotic therapy provides an additional benefit in the control of exacerbations in selected patients, but it may also have important side effects, and the possible development of resistance must always be borne in mind. ${ }^{12}$ In this regard, the Spanish COPD Guidelines (Spanish acronym GesEPOC) provide recommendations on the long-term use of antibiotics. Macrolides may be indicated in patients with frequent exacerbations requiring multiple courses of antibiotics despite optimized treatment, especially in patients who also have bronchiectasis on chest computed tomography (CT) and/or isolation of PA in sputum. ${ }^{18}$ Liver function should be monitored before and during treatment; atypical mycobacterial infections should be ruled out by specific culture, as well as the presence of arrhythmias through an electrocardiogram. Finally, macrolide use should be avoided in patients with hearing problems. The proposal is a regimen of $500 \mathrm{mg}$ of azithromycin three times a week in the winter months. The long-term use of quinolones must be even more restrictive because of the possible development of quinolone resistance and the caveat that $\mathrm{CBI}$ due to quinolone-resistant PPMs (especially PA or Stenotrophomonas) must be previously ruled out. The guidelines recommend that prescription should take place at reference centers under strict clinical and microbiological control. ${ }^{18}$

\section{The role of inflammation and its treatment in frequent COPD exacerbations}

Inflammation is important not just in the context of COPD exacerbations but in the stable phase as well. Both the GOLD document and the GesEPOC guideline state that the pulmonary inflammation is an essential component of the disease, which develops as an abnormal response to certain harmful particles, especially tobacco smoke, and depending on the genetic background of each individual. ${ }^{12,19}$ Inflammation develops not only in the airways but also systemically and may be associated with comorbidities that worsen the prognosis. The inflammatory process is modulated by various pathological mechanisms involving cells such as $\mathrm{CD}^{+} \mathrm{T}$ lymphocytes, especially macrophages and neutrophils. ${ }^{3}$

Initially, exposure to certain noxious agents such as cigarette smoke, viruses, or bacteria causes a response that is mediated basically by macrophages and neutrophils in the bronchial tree with the release of proinflammatory cytokines. This eventually causes a narrowing of the airway due to collagen deposition, an increase in the lymphoid follicles in the bronchial wall, thickening of the epithelial basal membrane, and release of an inflammatory exudate with reduced lumen. ${ }^{20}$ Depending on the pathways involved in the inflammatory process, the initial participation of macrophages and dendritic cells gives rise to the activation of monocytes, fibroblasts, $\mathrm{CD}^{+} \mathrm{T}$ cells, and neutrophils; this triggers, to a greater or lesser extent, the processes of bronchiolitis, fibrosis, emphysema, and/or mucus hypersecretion that can be found in patients with COPD. ${ }^{21}$ However, it has also been reported that some patients with COPD develop an inflammatory process caused by cytokines (mainly interleukins (ILs)-4 and -5), through the involvement of eosinophils, thus defining a specific feature of these patients. ${ }^{22}$ 
Inflammation of the airways is associated with disease severity and exacerbation episodes. Thus, patients with major airway obstruction and recurrent exacerbations are affected by greater local inflammation. ${ }^{23}$ Furthermore, inflammation (measured by the percentage of neutrophils in sputum) has been associated with a greater loss of lung function, and so these inflammatory mechanisms are also related to disease progression. ${ }^{24}$ When the inflammatory mediators involved in exacerbations of COPD are analyzed and compared with those identified in asthma, the participation of the cell groups is different; in COPD, macrophages, neutrophils, and CD8 ${ }^{+}$ $\mathrm{T}$ cells are primarily involved, while in asthma, mast cells, eosinophils, and $\mathrm{CD} 4^{+} \mathrm{T}$ lymphocytes predominate, with a lower representation of macrophages. The proinflammatory cytokines and their effects at the tissue level also differ: the main protagonists are leukotriene $\mathrm{B} 4, \mathrm{IL}-8$, tumor necrosis factor- $\alpha$, and reactive oxygen species in COPD, and leukotriene D4, histamine, IL-4, IL-5, and reactive oxygen species in asthma. The effects of this inflammation become apparent mainly in the peripheral airways in patients with COPD, with destruction of lung parenchyma, fibrosis, and squamous metaplasia. In patients with asthma, basically the whole airway is affected, with mild fibrosis and thickening of the basal membrane, and response to steroid treatment is better than in COPD..$^{25}$

Despite these clear differences between asthma and COPD, a group of patients share the characteristics of both diseases. This situation may affect their evolution and response to treatment. Recently, this syndrome has been termed the asthma-COPD overlap syndrome (ACOS), and the typical patient is an asthmatic long-term smoker who has developed an incompletely reversible airflow obstruction. ${ }^{26}$ A group of Spanish experts established diagnostic criteria for ACOS in patients with COPD, which were implemented in the GesEPOC guideline. ${ }^{18,27}$ The criteria were previous history of asthma in a patient with COPD, reversibility of the obstruction, and eosinophilic or Th2 inflammation that responds to the use of ICSs. ${ }^{28}$ The percentage of patients with COPD who belong to the ACOS group depends on the criteria used for diagnosis but ranges between $10 \%$ and $25 \% .{ }^{26}$ Currently, there are no conclusive data on the use of biomarkers for the diagnosis of ACOS, but a prior diagnosis of asthma in patients with COPD can be a key factor for selecting patients who require further study in order to identify this syndrome..$^{29,30}$

The treatment of inflammation in patients with COPD and the frequent exacerbator phenotype is outlined in guidelines, which recommends a series of drugs for controlling the inflammatory mechanisms of the disease. Among the most important are ICSs, which, when used in combination with long-term beta- 2 agonists (LABAs), have proven effective in improving symptoms and lung function and in reducing exacerbations. ${ }^{18,19,31}$ However, ICS therapy is associated with several adverse effects, including an increased risk of pneumonia. ${ }^{31,32}$

The use of corticosteroids reduces sputum eosinophilic inflammation..$^{33}$ For this reason, patients with ACOS, who usually present with sputum eosinophilia, may respond well to ICS treatment. ${ }^{34}$ The GesEPOC guideline recommends the early use of ICS in patients with ACOS and adjustment of the dose in accordance with clinical controls, lung function, and if possible, the presence of sputum eosinophilia. ${ }^{18}$

The use of ICSs in COPD is widespread and sometimes does not follow the approved indications. ${ }^{32}$ In these cases, their withdrawal should be considered. However, the data from the COPE study showed that the interruption of ICS in patients with moderate-to-severe COPD may accelerate the recurrence of exacerbations and increase the rate of decline in forced expiratory volume in 1 second $\left(\mathrm{FEV}_{1}\right)$ leading to a significant deterioration in quality of life. ${ }^{35}$ Another recent study in a group of patients with severe COPD with at least one exacerbation in the previous year and receiving treatment with triple therapy (LABA/ICS + long-acting anticholinergic) compared the effect of withdrawing ICS and continuing triple therapy over a follow-up period of 12 months. In this study, the risk of exacerbation did not increase in patients who discontinued treatment with ICS. ${ }^{36}$ However, the group that abandoned ICS therapy showed a loss of lung function (43 $\mathrm{mL}$ of $\mathrm{FEV}_{1}$ at week 52), although this loss was below the threshold considered clinically significant and was not accompanied by a significant impairment in quality of life or dyspnea. ${ }^{36}$

Roflumilast is a phosphodiesterase-4 inhibitor which also has an anti-inflammatory effect, and is indicated for patients with severe COPD with chronic bronchitis and frequent exacerbations. ${ }^{18}$ In a recent 1 -year study, roflumilast was effective in reducing severe exacerbations requiring hospitalization in patients receiving treatment with LABA/ICS, and even in the $70 \%$ receiving triple therapy with LABA/ICS + long-acting anticholinergic. ${ }^{37}$ In real life, however, tolerance of roflumilast is worse than in clinical trials, and so its use in patients with severe COPD may be limited by adverse events. ${ }^{38}$ The most common side effects are gastrointestinal disorders and weight loss.

Finally, although it is not an anti-inflammatory treatment, the possibility that respiratory rehabilitation may play a role 
in the control of exacerbations in patients with COPD has also been considered. There is some evidence that rehabilitation may decrease the rate of readmissions and improve symptoms and patients' quality of life. ${ }^{39}$ Respiratory rehabilitation improves the degree of dyspnea and lengthens the time until the next exacerbation in patients with a high exacerbation risk. ${ }^{40}$ Rehabilitation helps patients to increase their daily physical activity, which is a prognostic factor in COPD. ${ }^{41}$

\section{Discussion}

\section{Does CT have a role in the evaluation of patients with frequent exacerbations?}

Some severe patients continue to suffer exacerbations despite receiving the best $\mathrm{BD}$ and anti-inflammatory treatment available. In these cases, it is believed that infection plays a major role in the recurrence of exacerbations. In some patients with COPD and multiple exacerbations, ineffective mucociliary clearance facilitates PPM colonization of the airways, causing inflammation. This is followed by the manifestation of increased respiratory symptoms and an increase in the rate of exacerbations, which constitutes the CBI. ${ }^{10,42}$

High-resolution chest CT scans indicate the presence of bronchiectasis in up to $60 \%$ of patients with COPD and $\mathrm{FEV}_{1}<50 \%$, and bronchiectasis in COPD is associated with worse prognosis. ${ }^{11,43}$

Therefore, CBI and the presence of bronchiectasis increase the risk of exacerbations and aggravate COPD outcome. Today, several scoring systems have been validated for characterizing and assessing the extent of bronchiectasis, but since not all the published studies use the same criteria, their interpretation is difficult. The most widely recommended system is the one proposed by Smith et al that quantifies the extent of bronchiectasis in each lobe, with an overall score between 0 and 24 points. ${ }^{44}$

All participants in the expert panel discussion agreed that in patients with frequent exacerbations, the presence of bronchiectasis should be assessed with high-resolution chest $\mathrm{CT}$, as its identification is associated with worse prognosis and with an increased risk of recurrent exacerbations and CBI. Patients with bronchiectasis and COPD exacerbations should be treated for COPD and also according to the currently approved bronchiectasis protocols and standards of treatment. $^{45}$

\section{Should active attempts be made to isolate PA and identify $\mathrm{CBI}$ in cultures?}

The patients with COPD and frequent exacerbations who present the highest degree of complexity are those with greater airflow obstruction and respiratory infections due to unusual PPMs such as PA, which is associated with increased mortality. ${ }^{10,46,47}$ Some of the known risk factors for infection by PA in COPD are shown in Table 2. Clinical guidelines recommend antipseudomonal empirical treatment in patients with very severe COPD $\left(\mathrm{FEV}_{1}<30 \%\right)$ who have received antibiotics in the last 3 months or four courses of antibiotics over the last year, or in patients with prolonged treatment with systemic corticosteroids. ${ }^{48}$ However, bronchiectasis is not included within these risk factors related to PA, although its prevalence may be up to $60 \%$.

In a recent study carried out in a respiratory day unit and aimed to describe the characteristics and risk factors for PA infection in severe COPD $\left(\mathrm{FEV}_{1}<50 \%\right)$ and frequent exacerbations followed up over $\sim 3$ years, bronchiectasis was recorded in $47 \%$ of patients, and PA was isolated in $35 \%$ of them during exacerbations. Furthermore, the main risk factor associated with PA infection was the extent of bronchiectasis, followed by the number of previous courses of antibiotics. ${ }^{49}$ When comparing patients with and without isolated PA, no differences in lung function, BODE index, or comorbidities were found; however, patients with PA had longer hospital stay, greater need for oral corticosteroids, and increased mortality. ${ }^{49}$

Regarding bronchial colonization (or CBI) by PA in this same cohort and applying the classic criteria of three isolations or more separated by at least 1 month over a period of 6 months, $12 \%$ of patients with an initial isolation of PA eventually presented CBI due to this microorganism,

Table 2 Risk factors for Pseudomonas aeruginosa infection in COPD

\begin{tabular}{|c|c|}
\hline Study & Risk factors \\
\hline Allegra et al ${ }^{62}$ & $\mathrm{FEV}_{1}<35 \%$ \\
\hline \multirow[t]{2}{*}{ Eller et al ${ }^{63}$} & $\mathrm{FEV}_{1}<35 \%$ \\
\hline & Pretreatment with antibiotics \\
\hline Miravitlles et al ${ }^{6}$ & $\mathrm{FEV}_{1}<50 \%$ \\
\hline \multirow[t]{3}{*}{ Lode et $\mathrm{al}^{64}$} & $\mathrm{FEV}_{1}<35 \%$ \\
\hline & Use of systemic corticosteroids \\
\hline & Antibiotics in the previous 3 months \\
\hline \multirow[t]{4}{*}{ Monsó et al ${ }^{65}$} & Low FEV \\
\hline & Use of oral corticosteroids \\
\hline & Antibiotics in the previous 3 months \\
\hline & Protective effect of influenza vaccine \\
\hline \multirow[t]{4}{*}{ García-Vidal et al ${ }^{66}$} & Use of systemic corticosteroids \\
\hline & High BODE index \\
\hline & Hospital admission in the previous year \\
\hline & Previous isolation of $P$. aeruginosa \\
\hline \multirow[t]{2}{*}{ Gallego et $\mathrm{al}^{49}$} & Presence and extent of bronchiectasis \\
\hline & Prior exposure to antibiotics \\
\hline
\end{tabular}

Abbreviation: $\mathrm{FEV}_{1}$, forced expiratory volume in I second. 
as demonstrated by a pattern of clonal persistence of the initially isolated PA strain. The same strain of PA was not isolated again in the remaining patients; some acquired new strains of PA and eradicated them during the follow-up, and others showed patterns of clonal persistence or alternation but did not fulfill the criteria for CBI. In those with CBI, it was not associated with the extent of bronchiectasis, nor was any clonal transmission observed between patients with COPD. ${ }^{49}$ Among other important aspects to bear in mind in clinical practice are the PA morphotypes, since mucoid morphotypes are associated with resistance mechanisms and virulence, while normal or nonmucoid morphotypes are not. This distinction may be clinically relevant. ${ }^{50}$

As expected, culture-independent techniques, such as studies of the bronchial microbiome in patients with severe COPD, showed that patients colonized by PA have a higher prevalence of the genus Pseudomonas compared with patients not colonized by PA, as do conventional microbiological cultures. In these cases, the rest of the bronchial microbiome was similar in patients colonized and noncolonized by PA. Moreover, patients with and without colonization by PA had a similar microbiome during exacerbations. ${ }^{51}$

In view of the above, participants in the expert panel discussion agreed that active attempts should be made to isolate PA in serial sputum cultures in patients with severe COPD and frequent infective exacerbations.

\section{In the light of the above, which antibiotic should be administered to a patient colonized with PA who has an infectious exacerbation?}

The first point to consider is the pattern of PA resistance to commonly used antibiotics. If $\mathrm{CBI}$ is due to a quinolonesensitive PA, the best option would be oral ciprofloxacin at high doses (750 mg bid) over a period of 2-3 weeks. The use of parenteral antibiotics with antipseudomonal activity should be reserved for severely ill patients or those with prior treatment failures. It should also be considered that not all the exacerbations in a patient colonized by PA are caused by this microorganism. In fact, $\sim 50 \%$ are due to usual bacteria; therefore, microbiological assessment of exacerbations is important in order to guide the choice of the most appropriate antibacterial agent. Another empirical oral treatment option in this situation is the use of high-dose levofloxacin (500 mg bid), which has good activity against usual microorganisms such as $H$. influenzae and $S$. pneumoniae and acceptable activity against quinolone-sensitive PA. ${ }^{48}$

\section{Is inhaled antibiotic therapy ever indicated in patients with COPD?}

Inhaled antibiotics represent a very attractive therapeutic option, since these drugs may achieve a high concentration in the airways with low systemic exposure. As a consequence, the side effects are minor and relatively well tolerated, the most common being wheezing and local irritation, which are easily controlled with BDs. This therapy is indicated in cystic fibrosis and also in noncystic fibrosis bronchiectasis, but scientific evidence in patients with COPD is scarce. A previous small study assessing the effect of nebulized tobramycin twice a day for 14 days in patients with severe COPD colonized by multiresistant PA found reductions in local inflammation and bacterial load (and even eradication in some patients), and finally a $42 \%$ reduction in severe exacerbations after 6 months of treatment. ${ }^{52}$ Phase II clinical trials of the use of inhaled antibiotics in CBI due to PA in patients with COPD are currently underway.

The expert panel did not reach agreement on this point. At present, the use of inhaled antibiotics in patients with COPD and CBI is not indicated because their efficacy has not been demonstrated and the clinical experience is very limited. However, in a pilot study conducted at a day hospital unit specialized in patients with severe and very severe COPD and a high risk of exacerbations by PA, tolerance to treatment with inhaled nebulized colimycin was good, with an adherence of $88 \%$. A preliminary analysis also recorded a significant reduction in the number of exacerbations and emergency visits during a year of follow-up in these patients. ${ }^{53}$

\section{Does it make sense to treat respiratory viruses if a viral exacerbation is suspected?}

There was consensus among participants that the only viral infection associated with COPD exacerbation that can be treated is influenza A (H1N1), for which a specific antiviral agent and a hospital-based diagnostic test are available. Antiviral treatment should be started early, since the viral load has been reported to remain high in the first 7 days after onset of symptoms. ${ }^{54}$

\section{Are antipneumococcal and influenza vaccines recommended for all patients with COPD?}

In the case of antipneumococcal vaccine, the use of the conjugate vaccine with 13 serotypes is recommended because patients with COPD are a risk group for pneumococcal infection. ${ }^{55}$ However in countries such as Spain, the cost of 
the vaccine is not reimbursed for patients with COPD by the public health insurance. The only exception are those with an additional condition, such as the continued use of corticosteroids or other pathology associated with immunosuppression. Annual influenza vaccination is indicated for all patients with COPD.

However, all authors agreed that having an effective vaccine against $H$. influenzae would probably be much more useful than the pneumococcal vaccine, given the frequency of this microorganism as the cause of exacerbations of COPD.

\section{What is the recommendation for the use of oral azithromycin - only in the winter months, or throughout the year?}

In clinical practice, the use of azithromycin in COPD has followed the example of cystic fibrosis, that is, continuous administration throughout the year. Its use in the winter months is recommended in the GesEPOC guidelines to try to reduce antibiotic exposure without loss of effectiveness, but no clear evidence exists in favor of this strategy. ${ }^{18}$ It has to be considered that the anti-inflammatory effect of macrolides may take several weeks to appear; in consequence, therapy should be initiated before the onset of winter.

The use of azithromycin should be considered when the patient continues to experience infectious exacerbations despite optimal respiratory treatment. In these circumstances, the benefits appear to outweigh the risks, although close monitoring of the patient is crucial to detect early adverse effects associated with the use of the macrolide. ${ }^{12}$ Most of the participants in the expert panel prescribe treatment with azithromycin in patients with recurrent exacerbations (usually more than three in 1 year). Some discontinue the treatment in summer, but others maintain it throughout the year if the patient does not show side effects.

\section{Should a patient who has required systemic corticosteroids for a single exacerbation start ICS treatment in order to prevent further exacerbations?}

At present, there is not enough evidence to support initiating ICS treatment after a single exacerbation and maintaining it chronically in all cases. Although ICSs have been shown to reduce exacerbations in patients with COPD, they are not exempt from side effects. ${ }^{31}$ In the daily clinical practice of most of the participants in the discussion, ICS treatment is usually administered only temporarily in these cases or at progressively reduced doses, depending on the severity of airflow obstruction or the risk of adverse events in each particular patient.

\section{What role does systemic inflammation play in the prognosis of these patients?}

The existing evidence suggests that systemic inflammation may play a key role in the development of various comorbidities associated with COPD, and may thus affect patient prognosis. However, all participants agreed that there is no specific treatment aimed at controlling systemic inflammation in COPD.

\section{What is the experience of the efficacy and safety of roflumilast?}

All expert panel participants reported that roflumilast was poorly tolerated by a high percentage of patients, who develop gastrointestinal side effects in spite of the use of progressive doses or dose reduction in the case of an adverse event. However, patients who tolerate roflumilast will benefit from it, with a reduction in the frequency of exacerbations and slight increase in lung function. Therefore, roflumilast should be tested in patients in whom it is indicated, that is, those with severe COPD with chronic bronchitis and frequent exacerbations despite maximum inhaled treatment.

Even though the use of roflumilast is recommended in the main clinical practice guidelines, experience with its use as an anti-inflammatory agent is not comparable with that of ICS; far more is known of the safety profile of ICSs and their long-term benefits.

\section{According to current guidelines, patients with COPD without exacerbations should not use ICS, but what about those with chronic local inflammation and the resulting loss of lung function?}

It has been reported that patients with COPD present sustained lung inflammation even in the stable state and may suffer a loss of lung function after ICS withdrawal.

The consensus among participants was that the decision to withdraw ICSs should be individualized, after weighing up the risk of pneumonia, the possible loss of lung function, and other adverse effects, against their efficacy in reducing the frequency of exacerbations. During the process of withdrawal of ICS, patients must be closely monitored. ${ }^{32}$

An alternative is to reduce the dose of ICS in patients with COPD without exacerbations, who are receiving high 
doses despite no particular benefits of the high doses of ICS over lower doses in COPD have been reported.

\section{Conclusion}

Inflammatory mechanisms play a key role in COPD, both in the progression of the disease and during exacerbations. The presence of inflammatory cells (primarily neutrophils and macrophages) increases with the severity of disease and contributes to the exacerbations and progressive loss of lung function.

ACOS is the term used to describe a subgroup of patients with COPD who present an asthma-like inflammation.

The most widely used anti-inflammatory agent in COPD is ICS. A better understanding of the different phenotypes of COPD should help to establish a more rational use of ICS. There are a variety of exacerbation phenotypes, which remain relatively stable over time; bacterial and viral phenotypes are the most frequent. Viral infections cause up to $30 \%$ of exacerbations of COPD, and these infections may precipitate secondary bacterial infection. CBI is also associated with frequent exacerbations, affecting lung function and worsening quality of life.

Long-term antibiotic treatment is effective in reducing exacerbations in carefully selected patients with COPD. It should be considered as an add-on therapy in patients with severe COPD and frequent exacerbations of infectious origin, who require multiple courses of antibiotics despite optimal pharmacological and nonpharmacological treatment. However, the indication should always be individualized, the adverse effects monitored, and strict clinical controls performed.

Inhaled antibiotics are a promising alternative in patients with COPD with frequent exacerbations and CBI, particularly in cases that do not respond to oral treatment or present significant adverse events. However, controlled studies are required to test their efficacy and safety and evaluate the possible development of antimicrobial resistance.

High-resolution chest CT is useful in patients with the frequent exacerbator phenotype for the diagnosis of bronchiectasis. In addition, serial sputum cultures will help to identify patients with CBI and specially when caused by unusual bacteria such as PA or Stenotrophomonas.

\section{Acknowledgments}

This manuscript is the transcription of an open clinical session held by the Catalan Pulmonology Society (Societat Catalana de Pneumologia) and coordinated by Salud Santos and Marc Miravitlles, with the participation of Alicia Marin, Joan Serra-Batlles, David de la Rosa, Ingrid Solanes, Xavier
Pomares, Marta López-Sánchez, and Mariana Muñoz-Esquerre. The meeting was sponsored by GlaxoSmithKline.

\section{Author contributions}

All authors contributed to conception, debating, drafting and critically revising the paper and agree to be accountable for all aspects of the work.

\section{Disclosure}

Marc Miravitlles has received speaker fees from Almirall, Boehringer Ingelheim, AstraZeneca, Chiesi, GlaxoSmithKline, Menarini, Teva, Grifols, and Novartis, and consulting fees from Almirall, Boehringer Ingelheim, GlaxoSmithKline, Gebro Pharma, CLS Behring, Cipla, MediImmune, Teva, Takeda, Novartis, and Grifols. The other authors have no conflicts of interest to report.

\section{References}

1. Hurst JR, Vestbo J, Anzueto A, et al; Evaluation of COPD Longitudinally to Identify Predictive Surrogate Endpoints (ECLIPSE) Investigators. Susceptibility to exacerbation in chronic obstructive pulmonary disease. N Engl J Med. 2010;363:1128-1138.

2. Miravitlles M, Calle M, Soler-Cataluña JJ. Clinical phenotypes of COPD. Identification, definition and implications for guidelines. Arch Bronconeumol. 2012;48:86-98.

3. Decramer M, Janssens W, Miravitlles M. Chronic obstructive pulmonary disease. Lancet. 2012;379:1341-1351.

4. Garcha DS, Thurston SJ, Patel AR, et al. Changes in prevalence and load of airway bacteria using quantitative PCR in stable and exacerbated COPD. Thorax. 2012;67:1075-1080.

5. Bafadhel M, McKenna S, Terry S, et al. Acute exacerbations of chronic obstructive pulmonary disease: identification of biologic clusters and their biomarkers. Am J Respir Crit Care Med. 2011;184:662-671.

6. Miravitlles M, Espinosa C, Fernández-Laso E, et al; Study Group of Bacterial Infection in COPD. Relationship between bacterial flora in sputum and functional impairment in patients with acute exacerbations of COPD. Chest. 1999;116:40-46.

7. George SN, Garcha DS, Mackay AJ, et al. Human rhinovirus infection during naturally occurring COPD exacerbations. Eur Respir J. 2014; 44:87-96.

8. Mallia P, Message SD, Gielen V, et al. Experimental rhinovirus infection as a human model of chronic obstructive pulmonary disease exacerbation. Am J Respir Crit Care Med. 2011;183:734-742.

9. Molyneaux PL, Mallia P, Cox MJ, et al. Outgrowth of the bacterial airway microbiome after rhinovirus exacerbation of chronic obstructive pulmonary disease. Am J Respir Crit Care Med. 2013;188: 1224-1231.

10. Matkovic Z, Miravitlles M. Chronic bronchial infection in COPD. Is there an infective phenotype? Respir Med. 2013;107:10-22.

11. Martínez-García MA, Soler-Cataluña JJ, Donat Sanz Y, et al. Factors associated with bronchiectasis in chronic obstructive pulmonary disease patients. Chest. 2011;140:1130-1137.

12. Miravitlles M, Anzueto A. Antibiotic prophylaxis in COPD: why, when, and for whom? Pulm Pharmacol Ther. 2015;32:119-123.

13. Spagnolo P, Fabbri LM, Bush A. Long-term macrolide treatment for chronic respiratory disease. Eur Respir J. 2013;42:239-251.

14. Albert RK, Connett J, Bailey WC, et al; COPD Clinical Research Network. Azithromycin for prevention of exacerbations of COPD. N Engl J Med. 2011;365:689-698. 
15. Han MK, Tayob N, Murray S, et al. Predictors of chronic obstructive pulmonary disease exacerbation reduction in response to daily azithromycin therapy. Am J Respir Crit Care Med. 2014;189:1503-1508.

16. Uzun S, Djamin RS, Kluytmans JA, et al. Azithromycin maintenance treatment in patients with frequent exacerbations of chronic obstructive pulmonary disease (COLUMBUS): a randomised, double-blind, placebo-controlled trial. Lancet Respir Med. 2014;2:361-368.

17. Sethi S, Jones PW, Theron MS, et al; PULSE Study Group. Pulsed moxifloxacin for the prevention of exacerbations of chronic obstructive pulmonary disease: a randomized controlled trial. Respir Res. 2010;11:10.

18. Miravitlles M, Soler-Cataluña JJ, Calle M, et al; Spanish Society of Pulmonology and Thoracic Surgery. Spanish COPD Guidelines (GesEPOC): pharmacological treatment of stable COPD. Spanish Society of Pulmonology and Thoracic Surgery. Arch Bronconeumol. 2012;48:247-257.

19. Vestbo J, Hurd SS, Agustí AG, et al. Global strategy for the diagnosis, management, and prevention of chronic obstructive pulmonary disease: GOLD executive summary. Am J Respir Crit Care Med. 2013;187: 347-365.

20. Barnes PJ, Shapiro SD, Pauwels RA. Chronic obstructive pulmonary disease: molecular and cellular mechanisms. Eur Respir J. 2003; 22:672-688.

21. Barnes PJ, Hansel TT. Prospects for new drugs for chronic obstructive pulmonary disease. Lancet. 2004;364:985-996.

22. Rutgers SR, Postma DS, ten Hacken NH, et al. Ongoing airway inflammation in patients with COPD who do not currently smoke. Thorax. 2000;55:12-18

23. Hogg JC, Chu F, Utokaparch S, et al. The nature of small-airway obstruction in chronic obstructive pulmonary disease. NEngl J Med. 2004;350: 2645-2653.

24. Stănescu D, Sanna A, Veriter C, et al. Airways obstruction, chronic expectoration, and rapid decline of $\mathrm{FEV}_{1}$ in smokers are associated with increased levels of sputum neutrophils. Thorax. 1996;51:267-271.

25. Fabbri LM, Romagnoli M, Corbetta L, et al. Differences in airway inflammation in patients with chronic fixed airflow obstruction due to asthma or chronic obstructive pulmonary disease. Am J Respir Crit Care Med. 2003;167:418-424.

26. Barrecheguren M, Esquinas C, Miravitlles M. The asthma COPD overlap syndrome (ACOS). Opportunities and challenges. Curr Opin Pulm Med. 2015;21:74-79.

27. Soler-Cataluña JJ, Cosío B, Izquierdo JL, et al. Consensus document on the overlap phenotype COPD-asthma in COPD. Arch Bronconeumol. 2012;48:331-337.

28. Christenson SA, Steiling K, van den Berge M, et al. Asthma-COPD overlap: clinical relevance of genomic signatures of Type 2 inflammation in COPD. Am J Respir Crit Care Med. 2015;191:758-766.

29. Miravitlles M, Soriano JB, Ancochea J, et al. Characterisation of the overlap COPD-asthma phenotype. Focus on physical activity and health status. Respir Med. 2013;107:1053-1060.

30. Barrecheguren M, Roman-Rodriguez M, Miravitlles M. Is a previous diagnosis of asthma a reliable criterion for asthma-COPD overlap syndrome (ACOS) in a patient with COPD? Int J Chron Obstruct Pulmon Dis. 2015;10:1745-1752.

31. Calverley PM, Anderson JA, Celli B, et al; TORCH Investigators. Salmeterol and fluticasone propionate and survival in chronic obstructive pulmonary disease. $N$ Engl J Med. 2007;356(8):775-789.

32. Alcázar Navarrete B, Casanova C, Miravitlles M, et al; Documento de consenso sobre el uso adecuado de los corticoides inhalados en la EPOC Study Group. Correct use of inhaled corticosteroids in chronic obstructive pulmonary disease: a consensus document. Arch Bronconeumol. 2015;51:193-198.

33. Leigh R, Pizzichini MM, Morris MM, et al. Stable COPD: predicting benefit from high-dose inhaled corticosteroid treatment. Eur Respir J. 2006;27:964-971.

34. Kitaguchi Y, Komatsu Y, Fujimoto K, et al. Sputum eosinophilia can predict responsiveness to inhaled corticosteroid treatment in patients with overlap syndrome of COPD and asthma. Int J Chron Obstruct Pulmon Dis. 2012;7:283-289.
35. van der Valk P, Monninkhof E, van der Palen J, et al. Effect of discontinuation of inhaled corticosteroids in patients with chronic obstructive pulmonary disease: the COPE study. Am J Respir Crit Care Med. 2002;166:1358-1363.

36. Magnussen H, Disse B, Rodriguez-Roisin R, et al; WISDOM Investigators. Withdrawal of inhaled glucocorticoids and exacerbations of COPD. N Engl J Med. 2014;371:1285-1294.

37. Martinez FJ, Calverley PM, Goehring UM, et al. Effect of roflumilast on exacerbations in patients with severe chronic pulmonary disease uncontrolled by combination therapy (REACT): a multicentre randomized controlled trial. Lancet. 2015;385:857-866.

38. Muñoz-Esquerre M, Diez-Ferrer M, Montón C, et al. Roflumilast added to triple therapy in patients with severe COPD: a real life study. Pulm Pharmacol Ther. 2015;30:16-21.

39. van Ranst D, Stoop WA, Meijer JW, et al. Reduction of exacerbation frequency in patients with COPD after participation in a comprehensive pulmonary rehabilitation program. Int J Chron Obstruct Pulmon Dis. 2014; 9:1059-1067.

40. Huertas D, López-Sánchez M, Mateu L, et al. Results of a pulmonary rehabilitation program (PRP) in COPD patients: differences in outcomes according to currently 2011 GOLD groups. Eur Respir J. 2014; 44(Suppl 58):630.

41. Garcia-Rio F, Rojo B, Casitas R, et al. Prognostic value of the objective measurement of daily physical activity in patients with COPD. Chest. 2012;142:338-346.

42. Marin A, Garcia-Aymerich J, Sauleda J, et al; PAC-COPD Study Group. Effect of bronchial colonisation on airway and systemic inflammation in stable COPD. COPD. 2012;9:121-130.

43. Martínez-García MA, de la Rosa Carrillo D, Soler-Cataluña JJ, et al. Prognostic value of bronchiectasis in patients with moderate-to-severe chronic obstructive pulmonary disease. Am J Respir Crit Care Med. 2013; 187:823-831.

44. Smith IE, Jurriaans E, Diederich S, et al. Chronic sputum production: correlations between clinical features and findings on high resolution computed tomographic scanning of the chest. Thorax. 1996;51: 914-918.

45. Vendrell M, de Gracia J, Olveira C, et al. Diagnóstico y tratamiento de las bronquiectasias [Diagnosis and treatment of bronchiectasis. Spanish Society of Pneumology and Thoracic Surgery]. Arch Bronconeumol. 2008; 44:629-640. Spanish.

46. Renom F, Yáñez A, Garau M, et al. Prognosis of COPD patients requiring frequent hospitalization: role of airway infection. Respir Med. 2010;104:840-848.

47. Almagro P, Salvadó M, Garcia-Vidal C, et al. Pseudomonas aeruginosa and mortality after hospital admission for chronic obstructive pulmonary disease. Respiration. 2012;84:36-43.

48. Miravitlles M, Monsó E, Mensa J, et al. Antimicrobial treatment of exacerbation in chronic obstructive pulmonary disease: 2007 consensus statement. Arch Bronconeumol. 2008;44:100-108.

49. Gallego M, Pomares X, Espasa M, et al. Pseudomonas aeruginosa isolates in severe chronic obstructive pulmonary disease: characterization and risk factors. BMC Pulm Med. 2014;14:103.

50. Murphy TF, Brauer AL, Eschberger K, et al. Pseudomonas aeruginosa in chronic obstructive pulmonary disease. Am J Respir Crit Care Med. 2008; 177:853-860.

51. Millares L, Ferrari R, Gallego M, et al. Bronchial microbiome of severe COPD patients colonised by Pseudomonas aeruginosa. Eur J Clin Microbiol Infect Dis. 2014;33:1101-1111.

52. Dal Negro R, Micheletto C, Tognella S, et al. Tobramycin nebulizer solution in severe COPD patients colonized with Pseudomonas aeruginosa: effects on bronchial inflammation. Adv Ther. 2008;25:1019-1030.

53. Manuel MJ, Muñoz-Ezquerre M, López-Sánchez M, et al. Adherencia $y$ efectividad en el control de exacerbaciones en pacientes con EPOC grave bajo el tratamiento con colimicina inhalada $\left(\operatorname{Promixin}^{\circledR}\right)$ en dispositivo I-neb [Effectiveness and adherence of inhaled colymycin in I-neb device (Promixin ${ }^{\circledR}$ ) for control of exacerbations in severe COPD patients]. Arch Bronconeumol. In: 46th National Congress Spanish Society of Pulmonology and Thoracic Surgery; 2012. Spanish. 
54. Perez-Padilla R, de la Rosa-Zamboni D, Ponce de Leon S, et al. Pneumonia and respiratory failure from swine-origin influenza A (H1N1) in Mexico. N Engl J Med. 2009;361:680-689.

55. Miravitlles M, Soler-Cataluña JJ, Calle M, et al. Spanish guideline for COPD (GesEPOC). Update 2014. Arch Bronconeumol. 2014; 50(Suppl 1):1-16.

56. Gómez J, Baños V, Simarro E, et al. Estudio prospectivo y comparativo (1994-1998) sobre la influencia del tratamiento corto profiláctico con azitromicina en pacientes con EPOC evolucionada [Prospective, comparative study (1994-1998) of the influence of short-term prophylactic treatment with azithromycin on patients with advanced COPD]. Rev Esp Quimioterap. 2000;13:379-383. Spanish.

57. Suzuki T, Yanai M, Yamaya M, et al. Erythromycin and common cold in COPD. Chest. 2001;120:730-733.

58. Seemungal TA, Wilkinson TM, Hurst JR, et al. Long-term erythromycin therapy is associated with decreased chronic obstructive pulmonary disease exacerbations. Am J Respir Crit Care Med. 2008;178: 1139-1147.

59. Pomares X, Montón C, Espasa M, et al. Long-term azithromycin therapy in patients with severe COPD and repeated exacerbations. Int J Chron Obstruct Pulmon Dis. 2011;6:449-456.
60. He ZY, Ou LM, Zhang JQ, et al. Effect of 6 months of erythromycin treatment on inflammatory cells in induced sputum and exacerbations in chronic obstructive pulmonary disease. Respiration. 2010; 80:445-452.

61. Blasi F, Bonardi D, Aliberti S, et al. Long-term azithromycin use in patients with chronic obstructive pulmonary disease and tracheostomy. Pulm Phamacol Ther. 2010;23:200-207.

62. Allegra L, Blasi F, Diano P, et al. Sputum color as a marker of acute bacterial exacerbations of chronic obstructive pulmonary disease. Respir Med. 2005;99:742-747.

63. Eller J, Ede A, Schaberg T, et al. Infective exacerbations of chronic bronchitis: relation between bacteriologic etiology and lung function. Chest. 1998;113:1542-1548.

64. Lode H, Allewelt M, Balk S, et al. A prediction model for bacterial etiology in acute exacerbations of COPD. Infection. 2007;35:143-149.

65. Monsó E, García-Aymerich J, Soler N, et al. Bacterial infection in exacerbated COPD with changes in sputum characteristics. Epidemiol Infect. 2003;131:799-804.

66. García-Vidal C, Almagro P, Romaní V, et al. Pseudomonas aeruginosa in patients hospitalised for COPD exacerbation: a prospective study Eur Respir J. 2009;34:1072-1078.
International Journal of COPD

\section{Publish your work in this journal}

The International Journal of COPD is an international, peer-reviewed journal of therapeutics and pharmacology focusing on concise rapid reporting of clinical studies and reviews in COPD. Special focus is given to the pathophysiological processes underlying the disease, intervention programs, patient focused education, and self management protocols.

\section{Dovepress}

This journal is indexed on PubMed Central, MedLine and CAS. The manuscript management system is completely online and includes a very quick and fair peer-review system, which is all easy to use. Visit http://www.dovepress.com/testimonials.php to read real quotes from published authors.

Submit your manuscript here: http://www.dovepress.com/international-journal-of-chronic-obstructive-pulmonary-disease-journal 